\title{
Developing a Badge System for a Community ESL Class Based on the Canadian Language Benchmarks
}

\author{
Robb Mark McCollum \\ Southern Utah University \\ Elena Tornar Reed \\ Southern Utah University
}

\begin{abstract}
Teaching multilingual, multilevel language classes presents many challenges including helping students learn level-appropriate language. This learner-centred approach is complicated in a multilevel classroom where the teacher cannot always focus on each student's needs. As a result, learner motivation and attendance are frequent problems. This article details the adaptation of the Canadian Language Benchmarks (CLB) into a badge system to help learners in a community English as a Second Language (ESL) program set and track personalized language learning goals. The authors explain the purposes of badges, including motivation and assessment, and describe how to create a CLB-based badge system for curriculum and assessment purposes. The authors also share feedback from students and instructors in the community ESL program about the badge-based curriculum.
\end{abstract}

\section{Résumé}

L'enseignement dans des classes multilingues et à multiniveaux présente de nombreux défis, y compris la nécessité d'aider les étudiants à apprendre et à pratiquer la langue de manière adaptée à leur niveau. Cette approche centrée sur l'étudiant est compliquée dans une classe à niveaux multiples, où l'enseignant ne peut pas toujours se concentrer sur les besoins de chaque étudiant. Par conséquent, la motivation et l'assiduité des étudiants sont un problème fréquent. Cet article détaille l'adaptation des Niveaux de Compétence linguistique canadiens (NCLC) à un système de badges, pour aider les étudiants dans un programme communautaire d'anglais langue seconde (ALS) à définir et à suivre des objectifs d'apprentissage linguistique personnalisés. Les auteurs expliquent les objectifs des badges, y compris la motivation et l'évaluation, et décrivent comment créer un système de badges basé sur le NCLC en l'incorporant à leur curriculum et leur système d'évaluation. Les auteurs partagent également les commentaires des étudiants et des instructeurs du programme communautaire d'anglais langue seconde vis-à-vis le curriculum basé sur les badges. 


\section{Developing a Badge System for a Community ESL Class Based on the Canadian Language Benchmarks}

This article is an exploratory study investigating the potential application of the Canadian Language Benchmarks (CLB) as a badge system for adult learners in a multilevel English as a Second Language (ESL) community education course. This practice-based article outlines the challenges of multilevel classes and explains the benefits of a badge system for such a context. The authors detail a recommended methodology for developing a badge system and summarize their own application of this methodology to a community ESL curriculum and share feedback from students and teachers on the suitability of the CLB for a badge-based curriculum. The authors conclude with classroom recommendations as well as suggestions for future research in badge-based language learning.

\section{The Challenges of a Multilevel Classroom}

Teaching multilingual, multilevel language classes presents many challenges including helping students develop skills in a classroom environment where the teacher cannot always focus on each individual student's needs. In such situations, students may become discouraged when portions of the class are targeted at a level too high or too low for their current proficiency level. Such is often the case in adult ESL community education courses where there is typically one teacher assigned to a class of students with varying levels of proficiency.

Teachers can best support learners' language development and improve their motivation to participate by selecting tasks that match learners' needs. The challenge is that some tasks will suit the needs of some students but not others. For example, some adult ESL students need to learn the words for numbers 0-10. However, more proficient students who attend the same class may want to practice other number skills, such as making change as a cashier.

When class time is spent on basic skills, more proficient learners may become bored. Likewise, if the lesson focuses on higher-level skills, beginners may feel lost and discouraged. It is important to effectively engage adult learners who may have family and work responsibilities. The time that they devote to their English class is valuable, and, if it is not used effectively, they may consider withdrawing from the class and abandoning formal English instruction. As a result, their English language development slows, limiting their chances of integrating into the wider community and qualifying for desirable employment (Neilsen, 2019).

When a program has more than one class or level, there is the challenge of placement. Even with the use of a placement test, both teachers and students may be unclear on the students' exact level of ability, especially when students have strengths and weaknesses across the four language skills that are not assessed by the test. This can result in students not getting the targeted instruction in the skills they need the most (Seaman, 2010). Furthermore, program objectives may not be written in language that students can understand, preventing them from diagnosing which outcomes they have already achieved and which ones they need to develop (Faez et al., 2011). 
An additional problem arises when higher-level students are bored with a lower level activity and have a low willingness to participate. In such situations, teachers may mistakenly interpret a student's lack of engagement as low proficiency in the language (Ushioda, 2008). Teachers and students would be better served by a system that helps students and teachers better identify students' strengths and weaknesses and offers a way that students can become more self-directed in their progress (Fang et al., 2018)

\section{Our Community ESL Program}

The problems described above were challenges we faced in our community ESL program at Southern Utah University (SUU) in the southwestern United States. We serve about 20 students in one class, representing a variety of cultures and languages. The program has two part-time teachers who plan together and alternate nights of instruction due to family and other work responsibilities. Both teachers are highly proficient, nonnative English speakers. They have great empathy for our immigrant students, given their experiences as English learners and immigrants to the United States.

Our community ESL program is funded through a grant from a local business, Zion's Bank, which helps pay for teachers' salaries and classroom materials.

Administrative support for the community ESL program is provided through staff from the American Language and Culture Center (ALCC) at SUU, which also administers an intensive academic English program for students who intend to study in degree-seeking programs at SUU.

Prior to the implementation of the CLB badge system, teachers and students expressed concerns with the structure of the ESL community class. Teachers were disappointed that nearly half of enrolled students had irregular attendance or dropped the course partway through the semester. Teachers also grappled with providing a worthwhile experience for learners of such varying proficiency levels. Students told instructors that they did not have time to participate in a class that did not consistently meet their needs. Even long-time students who remained committed to the course lamented the lack of progression they felt from one semester to another since there were no clearly defined levels or outcomes. Teachers approached ALCC administration with these concerns.

After listening to these concerns, ALCC administrators proposed a solution that combined the CLB with a badge system. The CLB is a set of language standards used to measure the level of English proficiency in second language users (Centre for Canadian Language Benchmarks [CCLB], 2012). The Niveaux de Compétence Linguistique Canadiens (NCLC) is the French language version of the standards. The CLB appealed to ALCC administrators because the standards are created with the needs of ESL immigrants in mind. Also, the CLB includes Can Do statements in language that is accessible to both ESL teachers and their students. ALCC administrators recognized that the CLB covers language proficiency from the level of a complete novice through the skill set of academic and professional language users, so the CLB would suit the language goals of all students in the community ESL program.

Introducing teachers to the CLB was not enough. Teachers needed a system for evaluating the proficiency of new students, tracking the progress of current students, and helping all students develop learner autonomy in their personal language learning goals. Together, the ALCC administrators and the ESL community teachers determined to 
develop a badge and checklist system that would help students and teachers measure and track individual students' language proficiency progress.

\section{Badges and Language Learning}

Language learning works best when students and teachers align their goals (Ushioda, 2008). This alignment is complicated in multilevel classroom contexts where students have a broad range of language proficiency and personal linguistic goals. Microcredentials, such as badges, can help teachers craft engaging and meaningful learning outcomes that suit the needs of all learners in a diverse classroom (Kamenetz et al., 2018).

Badges are evidence, physical or digital, of an accomplished outcome. Think of a merit badge earned in youth scout programs: to earn a merit badge, a scout completes a set of tasks that demonstrate competence in a particular domain. In a similar way, language learners can earn badges by identifying a set of desired competencies, practicing and acquiring those competencies, and then demonstrating proficiency to earn the badges.

An educational badge system can have several benefits for students. Although some proponents of badges tout their use for external credentialing between educational institutions and with prospective employers (MacArthur Foundation, 2013; Seitzinger, 2015; Zalaznick, 2015), we focus on their value in the classroom context.

A badge system can motivate learners. Badges can serve as short-term goals that keep learners interested in achieving a long-term goal (Ady et al., 2015). For example, in an adult community ESL course, a student might have a large goal of developing the English language skills necessary to work as a cashier. A badge system could separate that large goal into smaller units, such as proficiency with counting money, confidence in greeting and making small talk, and asking and answering simple questions. By dividing the large goal into smaller tasks, a student is more likely to achieve the large goal by developing confidence and motivation with smaller tasks (Boyer, 2018). Boyer also points out that a badge system can motivate students because it gives them the choice to set individualized educational goals that are relevant to their personal aims. This ability to determine individualized learning goals is important for adult learners (Mudzingwa, 2017) and is consistent with a study by Campbell et al. (2015) in which a task-based approach to an ESL curriculum for immigrants in British Columbia, Canada was used to allow for more learned-determined objectives as opposed to teacher-determined ones. That said, learners who have a less developed self-directed mindset could feel overwhelmed by these choices (Kamenetz et al., 2018), so teachers should offer guidance and direction as needed. As language learners practice setting and achieving goals through a badge system, not only can they develop their language proficiency, but the badge system can also help them develop good habit formation and a self-regulated attitude toward language learning (Boyer, 2018; Homer et al., 2018). Homer et al. suggest that learners who use a badgebased curriculum perform better on summative assessment language tasks than learners in a control group.

In addition to motivating students and helping them develop self-regulation, a badge system can help with self-assessment. Badges help learners better understand their current skillset through identification of their strengths and weaknesses (Seitzinger, 2015). This self-assessment is made easier when badges use simple, direct descriptions of tasks and behaviours. Additionally, learners develop competence in self-assessment through a 
curriculum that encourages them to evaluate their skills in comparison to the standards or benchmarks of a program (Hirvela \& Pierson, 2000). In their study of portfolio-based language assessment (PBLA) with adult immigrants to British Columbia, Canada, Drew and Mudzingwa (2018) found that learners responded positively to the self-directed and self-assessment features of PBLA that follow the same principles as badge-based learning.

The assessment benefits of badges also help instructors. A badge system can potentially help teachers identify which course outcomes are difficult for students, based on a list of which outcomes students have not completed (Homer et al., 2018; Seitzinger, 2015). Using this information, teachers can provide differentiated instruction, such as assigning foundational badge work to students who need practice with lower-level skills and advanced badge work to students who are ready for more complex tasks (Boyer, 2018; Kamenetz et al., 2018). Thus, badge systems have the advantage of helping teachers target the needs of individual students within a multilevel class.

Criticisms of badges include the potential of using badges to reward and reinforce behaviours instead of also encouraging proficiency in the primary domains of the learning context (Matthews, 2016). For example, a student could earn a badge for consistently completing homework each night for a month. Although there are clearly benefits to encouraging such behaviours in language learners, stakeholders should never confuse a behaviour-based badge with a competency-based outcome. For badges to be meaningful as a measure of language proficiency, stakeholders need to clarify the outcome of a badge and ensure that the system includes proficiency-based badges.

Another criticism of badges is that stakeholders, including employers, will not take the time to interpret the meaning of a learner's badges (Matthews, 2016). Consider a cashier badge for a community ESL program that is earned through mastery of English numerical vocabulary and oral interactions needed when working as a cashier. Even if an adult community ESL learner has completed the requirements of the cashier badge, potential employers may not be willing to put in the effort to understand whether the badge is meaningful and relevant to their hiring needs. However, a consequential value of such a badge is that the learners will better understand the program outcomes through the language of the badges and thus be able to better articulate the skills that they have acquired when advocating for themselves in job interviews or transferring education to a new institution (Boyer, 2018).

The many benefits of badges encouraged us to adopt such a system to address the concerns of both students and teachers in our adult community ESL program. We hoped to develop a system that would better motivate students and offer them a more personalized study plan to meet their personal and professional English language goals.

\section{A Method for Adapting the CLB to a Badge System}

Having chosen the CLB as the basis for our badge system, we needed to adapt the materials into a badge system. In general, we followed the badge creation process proposed by Diaz et al. (2015). They suggest (1) determining a master badge plan, (2) specifying the details for each badge, (3) ensuring badge's objectives can be assessed, (4) detailing the badge progression system, (5) designing the awarding process, (6) addressing technology issues, and (7) designing badge visuals. Because our study is a pilot, we focused primarily on the first four steps, and we built in a simple feedback survey from students to learn how 
they felt about the badge system. The last three steps were addressed by creating simple paper badge designs that would be given to students upon completion of any badge.

First, we reviewed the level descriptors to determine how our students'

proficiencies aligned with the CLB. Then we developed an extensive spreadsheet with each badge name, language skill, badge description, evaluation criteria and evidence, suggested assessment types, and alignment with other frameworks, including concordances with language proficiency guidelines, such as the Common European Framework of Reference (CEFR) and the American Council for the Teaching of Foreign Languages (ACTFL) proficiency guidelines (ACTFL and LTI, 2016).

Once we had determined the scope and content of each badge, we created studentfocused checklists for each badge. The checklists included Can Do statements for each main task that a student was required to perform to show proficiency in that skill at that level. We also created sample assessments that teachers could use to verify student ability either at placement time or when a student felt ready to complete the badge. We even created badge images that could be added to print certificates that would be awarded to students on completion of each badge.

Using the spreadsheet, teachers were able to plan a curriculum that covered the tasks that were most relevant to the ability of the learners in the program. Each learner was given a checklist for the badge(s) that best matched their current ability and goals. Teachers created weekly lesson plans that they shared with students to help them see how classwork related to their personal checklists. As students practiced tasks that related to the outcomes on their checklists, they were invited to arrange a time to pass off those outcomes with the teacher who then signed their checklists. Once a student completed all outcomes for a particular badge checklist, a paper badge certificate was awarded to that student in class.

\section{Results from Learners and Instructors}

Feedback from learners in the ESL community class was mixed. More proficient learners liked the checklists. They indicated that the checklists helped them self-evaluate and set personal goals for English language improvement. They also reported that the checklists helped them decide what skills to focus on when pursuing self-directed study in English. They would like to continue using the badge system and tracking their progress with the checklists. This is consistent with the findings of Drew and Mudzingwa (2018) whose participants in the PBLA study reported positive attitudes towards the goal-setting and self-assessment benefits of the PBLA model.

Many lower-level students found the checklists confusing. They felt that the vocabulary in the checklists was difficult to understand, so they could not use it for selfdirected study. However, some lower-level students did indicate that they found the checklists helpful during class time. They indicated that when the teacher explained an outcome that was listed on the checklist and then taught a lesson and led a class activity related to that outcome, it helped them better understand the purpose of the class session and the language of the outcome.

This feedback from both more proficient and lower-level learners suggests that the language in the badge system is currently worded at a level that is accessible by more proficient learners but not by lower-level students. If the vocabulary in the checklists is not accessible, it negates the main purposes of the badge system for lower-level students. 
Therefore, the teachers made the decision to revise the wording of the checklists for lowerlevel students, working with the students in class to select phrasing that would be meaningful to them. The teachers also suggested adding more examples of situations in which the outcomes were displayed to better illustrate the tasks to learners.

For their part, teachers greatly appreciated the badge and checklist system. Prior to the implementation of the badge system, teachers did not have a strong curriculum to guide their classes. They tried their best to design lessons that students would find useful, but they did not have a sense of overall progression with the series of lessons. The badge system helped teachers learn about the CLB guidelines and better understand what tasks were appropriate for differing levels of learners. They could use the checklists to guide their lesson planning and ensure that they were targeting tasks that were at-level and relevant to the specific students in the program. A similar positive response towards a taskbased ESL curriculum was reported by Campbell et al. (2015) in which teachers and learners both praised the instruction that focused on practical student needs beyond the classroom.

Teachers also liked the assessment features of the badge system. The assessments helped them more accurately define the ability of learners across the CLB levels and identify what skills and tasks should be taught. The assessments also helped the teachers envision additional formal and informal assessments that could be used to verify student mastery of the badge outcomes. One of the teachers' concerns prior to the implementation of the badge system was the ability to guide learners, especially more proficient learners, towards self-study practice that would be motivating and useful. Teachers indicated that the badge system was very effective in this regard. Teachers are hopeful that a revision of the checklist language will also make the badge system useful for lower-level learners.

Additional features of the badge system that could be improved are the creation of materials to facilitate lesson and self-study practice that align with the CLB levels. In particular, more proficient learners wanted audio and video materials that would help them practice the tasks in the listening badge sequence, given that the multilevel classroom environment did not always provide them with the listening skills challenge that they needed to progress through the CLB levels. Teachers would also like to expand the badge system to include reading and writing outcomes given that the current phase of the project focused on listening and speaking skills.

\section{Conclusion}

In our adult community ESL program, we found that adapting the CLB into a badge and checklist system helped teachers better articulate their curriculum and communicate their instructional goals to students. More proficient learners in the program responded well to the badge system, stating that it helped them set personal goals and focus on the tasks that would best help them progress in the language. Lower-level students struggled with the language of the checklists, so teachers collaborated with them to reword the outcomes and descriptors to better match their needs.

We encourage other programs to consider developing a CLB-based badge system to help increase motivation and self-regulation among immigrant learners. Even though adult learners face many obstacles in their pursuit of a new language, they need language training that builds their confidence in the new language and culture, which will also 
rebuild their identities as contributing members of local and national communities (Ghadi, et al., 2019). A CLB-based badge system can provide them with greater direction and empowerment through their language learning journey.

We also recommend that practitioners and researchers build upon this exploratory study by further investigating the usefulness of badges for language learning. Specifically, we encourage researchers to investigate how a badge system based on the CLB appeals to learners of varying proficiency levels and with different language learning goals. We also think it would be helpful to study how well learners are able to articulate their language skills to others, such as future educators and employers, based on the learners' use of a badge system. Finally, we encourage studies that compare the effectiveness of badge-based curricula for multilevel classes versus traditional curricula that do not offer as much individualized learning.

Correspondence should be addressed to Robb Mark McCollum

Email: robbmccollum@suu.edu

\section{References}

Ady, K. Kinsella, K., \& Paynter, A. (2015). Digital distinction: Badges add a new dimension to adult learning. Journal of Staff Development, 36(4), 24-27.

American Council on the Teaching of Foreign Languages (ACTFL), and Language Testing International (LTI). (2016). Alignment of the ACTFL proficiency ratings to the Canadian language benchmarks (CLB). Language Testing International. https://www.languagetesting.com/pub/media/wysiwyg/research/white_papers/Align ment_of_the_ACTFL_Proficiency_Ratings_to_the_CLB_D7.pdf

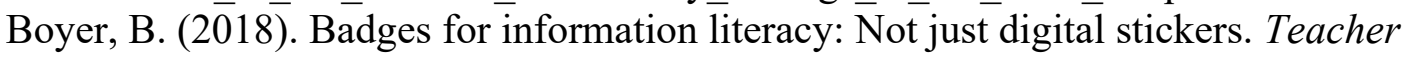
Librarian, 45(5), 22-26.

Campbell, C., MacPherson, S., \& Sawkins, T. (2015). Preparing students for education, work, and community: Activity theory in task-based curriculum design. TESL Canada Journal, 31, 68-92.

Centre for Canadian Language Benchmarks (CCLB). (2012). Canadian language benchmarks: English as a second language for adults. Citizenship and Immigration Canada.

Diaz, V., Finkelstein, J., \& Manning, S. (2015). Developing a higher education badging initiative. EDUCAUSE Learning Initiative (ELI) Briefs.https://library.educause.edu/-/media/files/library/2015/8/elib1504-pdf.pdf

Drew, R., \& Mudzingwa, C. (2018). The portfolio language assessment model: Perceptions of adult immigrant English language learners. BC Teal Journal, 3(1), 1-21.

Faez, F., Majhanovich, S., Taylor, S., Smith, M., \& Crowley, K. (2011). The power of "Can Do" statements: Teachers' perceptions of CEFR-informed instruction in French as a second language classrooms in Ontario. The Canadian Journal of Applied Linguistics, 14(2), 1-19.

Fang, T., Neil, K., Brake, D. R., \& Sapeha, H. (2018). Issues in providing English as a second language training to refugees: Lessons from Newfoundland and Labrador. The Morning Watch: Educational and Social Analysis, 46, 1-5. 
Ghadi, N., Massing, C., Kikulwe, D., \& Giesbrecht, C. J. (2019). Language and identity development among Syrian adult refugees in Canada: A Bourdieusian analysis. Journal of Contemporary Issues in Education, 14(1), 71-88.

Hirvela, A. \& Pierson, H. (2000). In G. Ekbatani \& H. Pierson (Eds.), Learner-directed assessment in ESL (pp. 105-126). Lawrence Erlbaum.

Homer, R., Hew, K. F., \& Tan, C. Y. (2018). Comparing digital badges-and-points with classroom token systems: Effects on elementary school ESL students' classroom behavior and English learning. Educational Technology \& Society, 21(1), 137-151.

MacArthur Foundation. (2013). What is a badge? MacArthur Foundation. https://www.macfound.org/videos/395/

Matthews, C. (2016). Unwelcome innovation. Inside Higher Ed. https://www.insidehighered.com/views/2016/09/22/essay-flawed-assumptionsbehind-digital-badging-and-alternative-credentialing

Mudzingwa, C. (2017). The portfolio-based language assessment (PBLA): Suitable for adult learners? BC Teal Journal, 2(1), 14-24.

Neilsen, K. (2019). Radical re-thinking required. Language Magazine. https://www.languagemagazine.com/2019/09/20/radical-re-thinking-required/

Seaman, A. (2010). Responding to the challenge of large mixed-ability classes in China. In B. Baurain \& Phan, L. H. (Eds.) Multilevel and diverse classrooms (pp. 9-21). TESOL, Inc.

Seitzinger, J. (2015). Open badges. TEDx Talks. https://youtu.be/DiTHIuqA0cc

Ushioda, E. (2008). Motivation and good language learners. In C. Griffiths (Ed.), Lessons from Good Language Learners (pp. 19-34). Cambridge University Press.

Zalaznick, M. (2015). Badges hit the big time. University Business. https:/www.universitybusiness.com/article/digital-badges-hit-big-time-higher-ed 